\title{
Effect of pressure on heat transfer coefficient at the metal/mold interface of A356 aluminum alloy
}

Fardi Ilkhchy, A.; Jabbari, Masoud; Davami, P.

Published in:

International Communications in Heat and Mass Transfer

Link to article, DOI:

10.1016/j.icheatmasstransfer.2012.04.001

Publication date:

2012

Document Version

Publisher's PDF, also known as Version of record

Link back to DTU Orbit

Citation (APA):

Fardi Ilkhchy, A., Jabbari, M., \& Davami, P. (2012). Effect of pressure on heat transfer coefficient at the $\mathrm{metal} / \mathrm{mold}$ interface of A356 aluminum alloy. International Communications in Heat and Mass Transfer, 39(5), 705-712. https://doi.org/10.1016/j.icheatmasstransfer.2012.04.001

\section{General rights}

Copyright and moral rights for the publications made accessible in the public portal are retained by the authors and/or other copyright owners and it is a condition of accessing publications that users recognise and abide by the legal requirements associated with these rights.

- Users may download and print one copy of any publication from the public portal for the purpose of private study or research.

- You may not further distribute the material or use it for any profit-making activity or commercial gain

- You may freely distribute the URL identifying the publication in the public portal 


\title{
Effect of pressure on heat transfer coefficient at the metal/mold interface of A356 aluminum alloy
}

\author{
A. Fardi Ilkhchy ${ }^{\text {a }}$, M. Jabbari ${ }^{\text {b,* }}$, P. Davami ${ }^{\mathrm{c}}$ \\ a A Young Researchers Club, Ilkhchi Branch, Islamic Azad University, Ilkhchi, Iran \\ b Department of Mechanical Engineering, Technical University of Denmark, Nils Koppels Allé, 2800 Kgs. Lyngby, Denmark \\ c Department of Materials Science and Engineering, Sharif University of Technology, P.O. Box 11365, Tehran, Iran
}

\section{A R T I C L E I N F O}

Available online 16 April 2012

\section{Keywords:}

Interfacial heat transfer coefficient

External pressure

Metallic mold

IHCP method

Finite difference method

\begin{abstract}
A B S T R A C T
The aim of this paper is to correlate interfacial heat transfer coefficient (IHTC) to applied external pressure, in which IHTC at the interface between A356 aluminum alloy and metallic mold during the solidification of casting under different pressures were obtained using the inverse heat conduction problem (IHCP) method. The method covers the expedient of comparing theoretical and experimental thermal histories. Temperature profiles obtained from thermocouples were used in a finite difference heat flow program to estimate the transient heat transfer coefficients. The new simple formula was presented for correlation between external pressure and heat transfer coefficient. Acceptable agreement with data in literature shows the accuracy of the proposed formula.
\end{abstract}

(c) 2012 Elsevier Ltd. All rights reserved.

\section{Introduction}

The contact interface between a mold and a casting has the great influence on cooling rate and solidification time. In the case of permanent mold casting, due to higher cooling rate as compared to sand casting, better control of the heat transfer and solidification phenomena is needed to improve the mechanical properties and soundness of the casting [1]. There is a considerable thermal resistance between cast and mold, because of gap existence among them. The heat transfer coefficient variation with time after pouring is the key factor to control the solidification. Several studies have attempted to quantify the transient interfacial metal/mold heat transfer coefficient, $h_{i}$, emphasizing different factors which affect heat flow across such interfaces during solidification [2-6]. These factors include the thermo-physical properties of contacting materials, casting geometry, orientation of casting-mold interface with respect to gravity (contact pressure), mold temperature, pouring temperature, roughness of mold contacting surface and mold coatings [7-10].

The way the heat flows across the metal and mold surfaces directly affects the evolution of solidification, and plays a notable role in determining the cooling conditions within the metal, mainly in foundry systems of high thermal diffusivity like chill castings [4]. The metal/ mold interface is in the form of imperfect junction, and this results in temperature drop. Two different contacting surfaces are illustrated in Fig. 1. Because the two surfaces in contact are not perfectly flat, when

\footnotetext{
th Communicated by: W.J. Minkowycz.

* Corresponding author.

E-mail address: mjab@mek.dtu.dk (M. Jabbari).
}

the interfacial contact pressure is reasonably high, most of the energy passes through a limited number of actual contact spots [11,12].

In the present study variation of interfacial heat transfer coefficient $\left(h_{i}\right)$ during solidification of Al-A356 was evaluated. Effect of different loads on the solidifying metal was investigated using mathematical modeling coupled with experimental. Results show that as the external load increases the heat transfer in the mold/metal improves by the decrease of gap. Consequently the heat transfer coefficient increases by the increase of external load, which a new and simple formula was proposed from experimental data.

\section{Governing equations}

The heat flow across the metal-mold interface can be characterized by a macroscopic average metal/mold interfacial heat transfer coefficient $\left(h_{i}\right)$ given by:

$h_{i}=\frac{q}{A\left(T_{C}-T_{M}\right)}$

where $q$ is the average heat flux across the interface; $T_{C}$ and $T_{M}$ are casting and mold surface temperatures $(K)$, respectively. Development of the used mathematical model is based on the general equation of heat conduction [11] expressed in cylindrical coordinate:

$\rho C_{P} \frac{\partial T}{\partial t}=\frac{1}{r} \frac{\partial}{\partial r}\left(k r \frac{\partial T}{\partial r}\right)+\frac{1}{r^{2}} \frac{\partial}{\partial \varphi}\left(k \frac{\partial T}{\partial \varphi}\right)+\frac{\partial}{\partial z}\left(k \frac{\partial T}{\partial z}\right)+\dot{q}$

where $\rho$ is density, $C_{P}$ is heat capacity, $k$ thermal conductivity of alloy, $\dot{q}$ the heat source and $r, z$ and $\varphi$ are the cylindrical. 

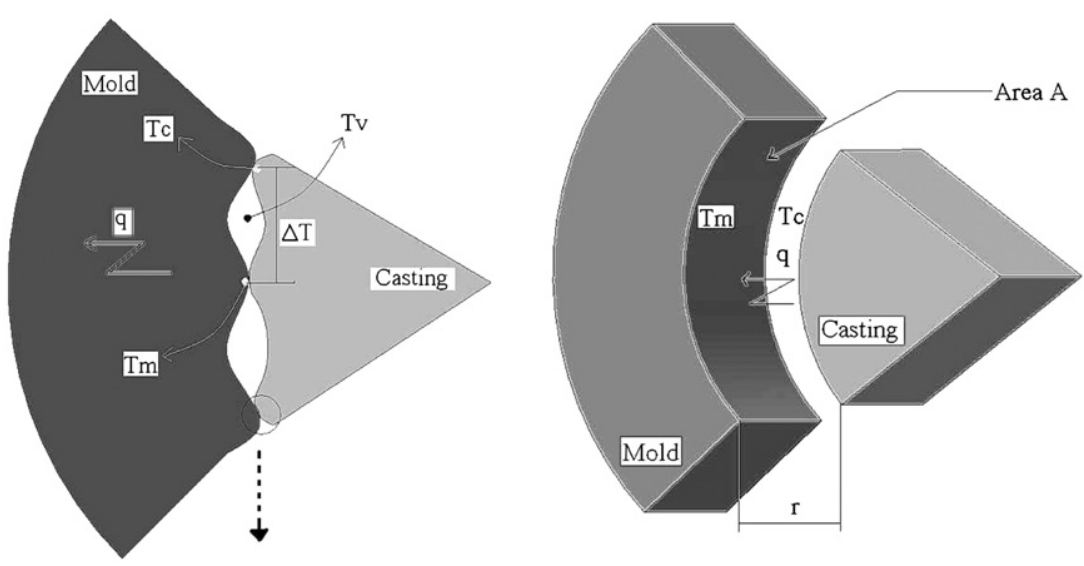

Fig. 1. Heat flow across permanent mold-casting interface for cylindrical coordinate.

Considering radial flow of heat as dominant heat transfer direction, Eq. (1) can be reduced to one-dimensional form. Thus, the direction $z$ of heat extraction can be neglected, once it is not significant regarding the heat flow in $r$ and $\varphi$ directions. In the case of ingots with a symmetrical section, the heat flow in the $\varphi$ direction can also be neglected, resulting in a simplified equation. Therefore, the one dimensional transient heat equation in cylindrical coordinates will be:

$\rho C_{P} \frac{\partial T}{\partial t}=\frac{k}{r} \frac{\partial}{\partial r}\left(r \frac{\partial T}{\partial r}\right)+\dot{q}$

The term of the heat generation of energy $(\dot{q})$ in the unsteady state condition is:

$\dot{q}=\rho \cdot \Delta H_{m} \cdot \frac{\partial f_{s}}{\partial t}$.

$\Delta H_{m}$ is the latent heat of fusion and $\partial f_{s}$ is the fraction of solid formed during the phase transformation which:

$\frac{\partial f_{s}}{\partial t}=\frac{\partial f_{s}}{\partial T} \cdot \frac{\partial T}{\partial t}$

For short or long freezing range alloys, the latent heat evolution was taken into account by using Scheil's equation until the remaining liquid reached the eutectic composition.

$f_{s}=1-\left(\frac{T_{m}-T}{T_{m}-T_{L}}\right)\left(1 /\left(k_{0}-1\right)\right)$

where $k_{0}$ is the distribution coefficient, $T_{m}$ and $T_{L}$ are melting point and liquidus temperature. By simplifying Eqs. (3)-(6) we have:

$\rho C_{P} \frac{\partial T}{\partial t}=\frac{1}{r} \frac{\partial}{\partial r}\left(k \cdot r \frac{\partial T}{\partial r}\right)+\rho \cdot \Delta H_{m} \cdot \frac{\partial f_{s}}{\partial T} \cdot \frac{\partial T}{\partial t}$.

Expanding the partial derivatives in relation to the radius and considering the material as isotropic, rearranging Eq. (7), it follows that:

$\rho\left(C_{P}-\Delta H_{m} \cdot \frac{\partial f_{s}}{\partial T}\right) \frac{\partial T}{\partial t}=k \cdot\left(\frac{\partial^{2} T}{\partial r^{2}}+\frac{1}{r} \frac{\partial T}{\partial r}\right)$

where:

$\dot{C}=\left(C_{P}-\Delta H_{m} \cdot \frac{\partial f_{s}}{\partial T}\right)$ and the cylindrical coordinate equation is reduced to:

$\frac{\partial T}{\partial t}=\frac{k}{\rho \dot{C}} \cdot\left(\frac{\partial^{2} T}{\partial r^{2}}+\frac{1}{r} \frac{\partial T}{\partial r}\right)$

Using the finite difference method (FDM) for the development of Eq. (8), we have:

$T_{i}^{n+1}=\frac{k \cdot \Delta t}{\rho_{i} \dot{C}_{i}}\left[\frac{T_{i-1}^{n}-2 T_{i}^{n}+T_{i+1}^{n}}{\Delta r^{2}}+\frac{1}{r_{i}} \cdot\left(\frac{T_{i+1}^{n}-T_{i-1}^{n}}{2 \Delta r}\right)\right]+T_{i}^{n}(i \neq 0)$

or:

$T_{i}^{n+1}=\frac{\Delta t}{\rho_{i} \cdot \dot{C}_{i} \cdot r_{i} \cdot \Delta r^{2}}\left[k \cdot r_{i-\frac{1}{2}} \cdot\left(T_{i-1}^{n}-T_{i}^{n}\right)+k \cdot r_{i+1} \cdot\left(T_{i+\frac{1}{2}}^{n}-T_{i}^{n}\right)\right]+T_{i}^{n}$.

Considering the metal/mold interface, the following thermal balance can be applied:

$T_{M / m}^{n+1}=\frac{\Delta t}{\rho_{i} \cdot \dot{C}_{i} \cdot r_{m} \cdot \Delta r}\left[h \cdot r \cdot\left(T_{a}^{n}-T_{m}^{n}\right)+k \cdot r_{m-\frac{1}{2}} \cdot\left(\frac{T_{m-1}^{n}-T_{m}^{n}}{\Delta r}\right)\right]+T_{M / m}^{n}$

where $T_{a}$, is ambient temperature, $r_{m}$, is the external radius of the cylindrical ingot; $T_{M / m}$, is the metal/mold interface temperature and $h$, it is the overall heat transfer coefficient between the casting surface and air.

The heat flow across the casting-mold interface can be characterized by Eq. (1) and $h$ can be determined provided that all the other terms of the equation, namely $q, T_{C}$ and $T_{M}$, are known [4]. However, it is difficult to measure these parameters because accurate locating of the thermocouples of finite mass at the interface is not an easy task, and they can distort the temperature gradient at the interface. To overcome this experimental impediment, the methods of calculation of $h_{i}$ existing in the literature are based on knowledge of other conditions, such as temperature histories at interior points of the casting or mold, together with mathematical models of heat flow during solidification. Among these methods, those based on the solution of the inverse heat conduction problem have been widely used in the quantification of the transient interfacial heat transfer [12]. Since solidification of a casting involves both a change of phase and temperature variable thermal properties, the inverse heat conduction becomes nonlinear. Most of the methods of calculation of timedependent $h_{i}$ existing in literature are based on numerical techniques, generally known as methods of solving the inverse heat conduction problem [13-16]. IHCP method is based on a complete mathematical description of physics of the process, supplemented with experimentally obtained temperature measurements in metal and/or mold. The inverse problem is solved by adjusting parameters in the mathematical description to minimize the difference between the model 


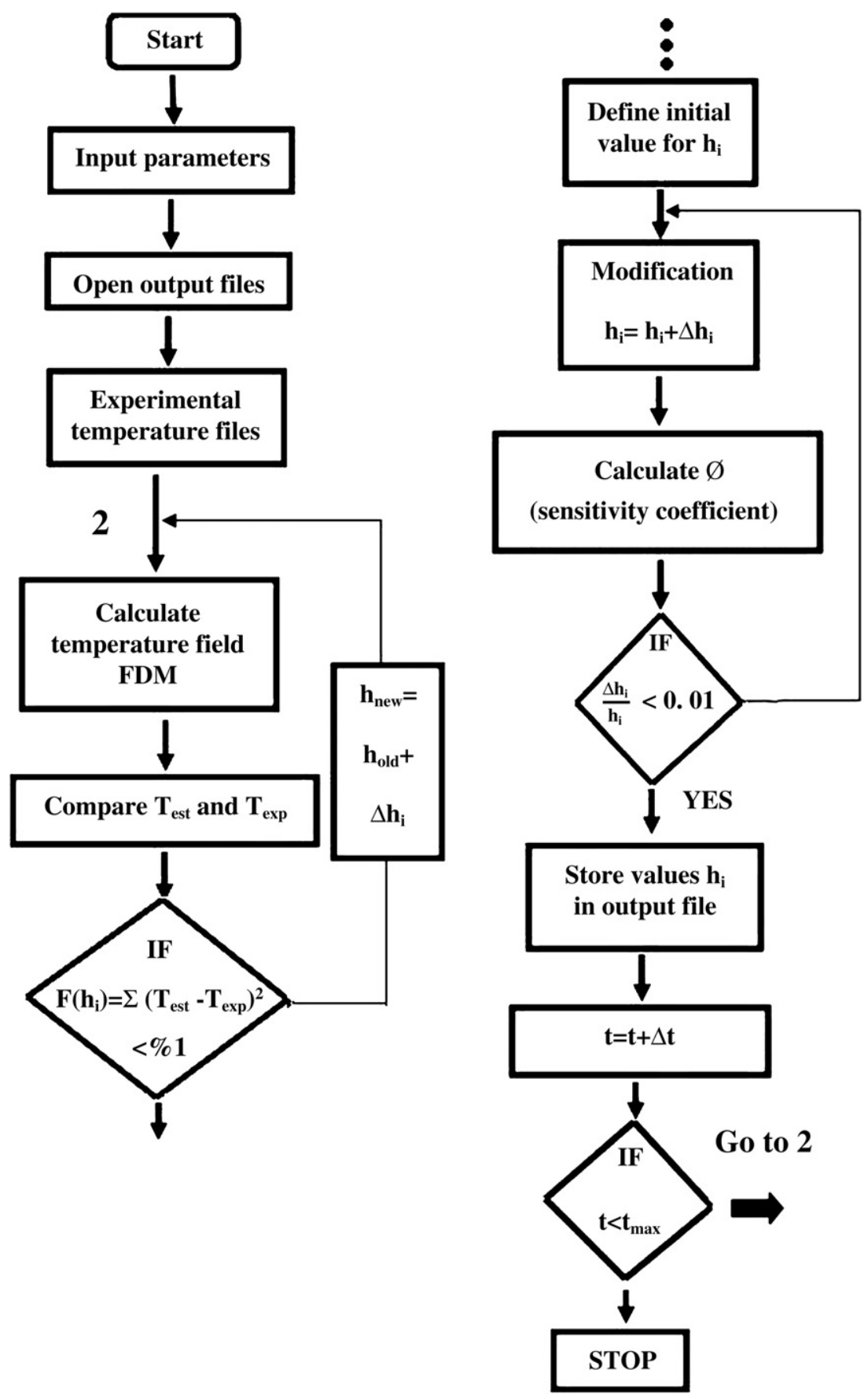

Fig. 2. Flow chart for the determination of metal/mold heat transfer coefficients.

computed values and the experimental measurements. Nonlinear estimation technique was used by Beck [15] for the numerical solution of this class of problem.

It has advantage over the other numerical in that Beck [15] studied the problem from the standpoint, effective treatment of experimental data, taking into account inaccuracies concerning the locations of

Table 1

Nominal composition of the commercial aluminum A356 used in this work.

\begin{tabular}{lllllllll}
\hline Element & $\mathrm{Si}$ & $\mathrm{Mg}$ & $\mathrm{Mn}$ & $\mathrm{Fe}$ & $\mathrm{Cu}$ & $\mathrm{Zn}$ & $\mathrm{Ti}$ & $\mathrm{Al}$ \\
\hline Amount (wt.\%) & 7.1 & 0.4 & 0.1 & 0.16 & 0.04 & 0.01 & 0.11 & $\mathrm{Bal}$ \\
\hline
\end{tabular}

Table 2

Casting and mold properties used for simulating of heat transfer.

\begin{tabular}{lcl}
\hline Properties & Metal & Mold \\
\hline$k_{s}\left(\mathrm{Wm}^{-1} \mathrm{~K}^{-1}\right)$ & 185 & 46 \\
$k_{l}\left(\mathrm{Wm}^{-1} \mathrm{~K}^{-1}\right)$ & 180 & - \\
$C_{s}\left(\mathrm{~J} \cdot \mathrm{kg}^{-1} \cdot \mathrm{K}^{-1}\right)$ & 1084 & 527 \\
$C_{l}\left(\mathrm{~J} \cdot \mathrm{kg}^{-1} \cdot \mathrm{K}^{-1}\right)$ & 1130 & - \\
$\rho_{s}\left(\mathrm{~kg} \cdot \mathrm{m}^{-3}\right)$ & 2600 & 7860 \\
$\rho_{l}\left(\mathrm{~kg} \cdot \mathrm{m}^{-3}\right)$ & 2500 & - \\
$\Delta H_{m}\left(\mathrm{~J} \cdot \mathrm{kg}^{-1}\right)$ & 421 & - \\
$K_{0}$ & 0.17 & - \\
$T_{s}$ & 609 & - \\
$T_{l}$ & 559 & - \\
\hline
\end{tabular}




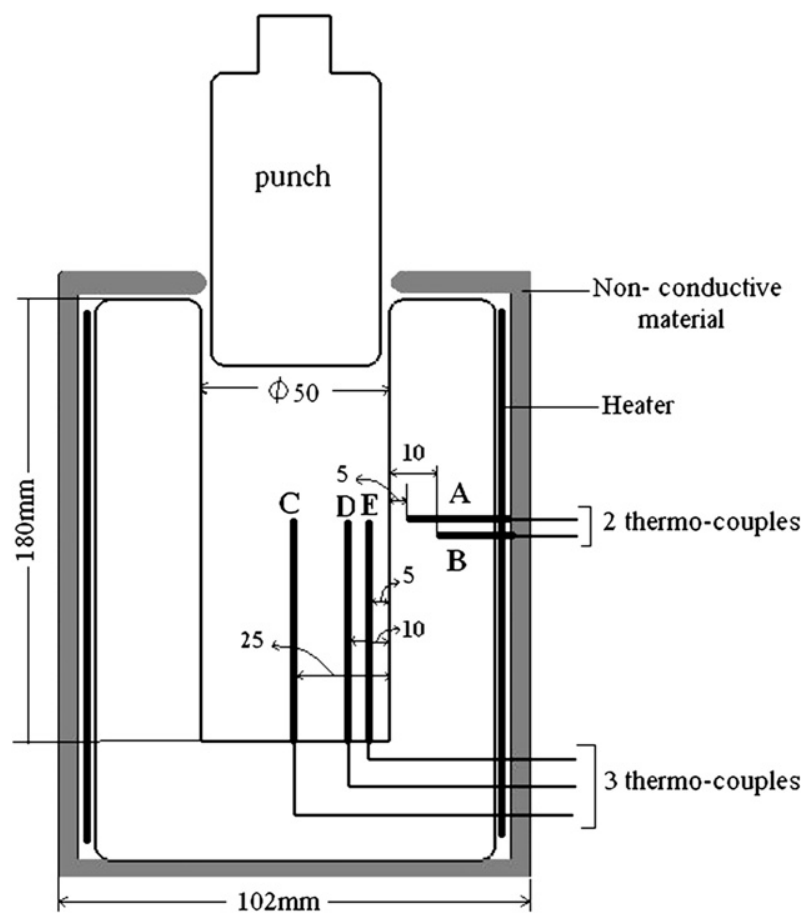

Fig. 3. Mold assembly and thermocouple position.

thermocouple places, statistical errors in temperature measurement and uncertainty in material properties. In the present work, a similar procedure used to determine the value of $h_{i}$ which minimizes an objective function defined by Eq. (14):

$F(h)=\sum_{i=1}^{n}\left(T_{\text {est }}-T_{\text {exp }}\right)^{2}$ where $T_{\text {est }}$ and $T_{\text {exp }}$ are, respectively, the estimated and experimentally measured temperatures at various thermocouple locations and times, and $n$ is the iteration stage. A suitable initial value of $h_{i}$ is assumed and with this value, the temperature of each reference location in casting and mold at the end of each time interval $\Delta t$ is simulated by using an explicit finite difference technique. The correction in $h_{i}$ at each iteration step is made by a $\Delta h_{i}$ value, and new temperatures are estimated. With these values sensitivity coefficients $(\psi)$ are calculated for any iteration; given by:

$\psi=\frac{T_{e s t}\left(h_{i}+\Delta h_{i}\right)-T_{e s t}\left(h_{i}\right)}{\Delta h_{i}}$.

The sequence of the equations involves the calculation of the sensitivity coefficients for measured temperatures. The assumed value of $h$ is corrected using Eq. (16):

$h_{i}($ new $)=h_{i}($ old $) \pm \Delta h_{i}$.

The mentioned procedure is repeated for a new $h$, and is continued until $\Delta h_{i} / h_{i}<0.01$. Calculation of $h$ as a function of time is continued until the end of the desired period. The flow chart, shown in Fig. 2, gives an overview of the solution procedure.

\section{Experimental procedure}

The commercial aluminum A356 with the nominal composition shown in Table 1 is used for the present study. The alloy was melted in an electric resistance-type furnace up to a predetermined temperature. Pouring temperature was approximately $730{ }^{\circ} \mathrm{C}$ (superheat $=0.2 T_{L}$ ). The mold was made of carbon steel and its inner surface was coated with graphite. The mold was preheated to $300{ }^{\circ} \mathrm{C}$ and, before pouring became stable using non-conductive materials. External loads were applied by an apparatus which was controlled by a hand crane and applied $10 \mathrm{~s}$ after pouring. Maximum available load is $300 \mathrm{~kg}$.

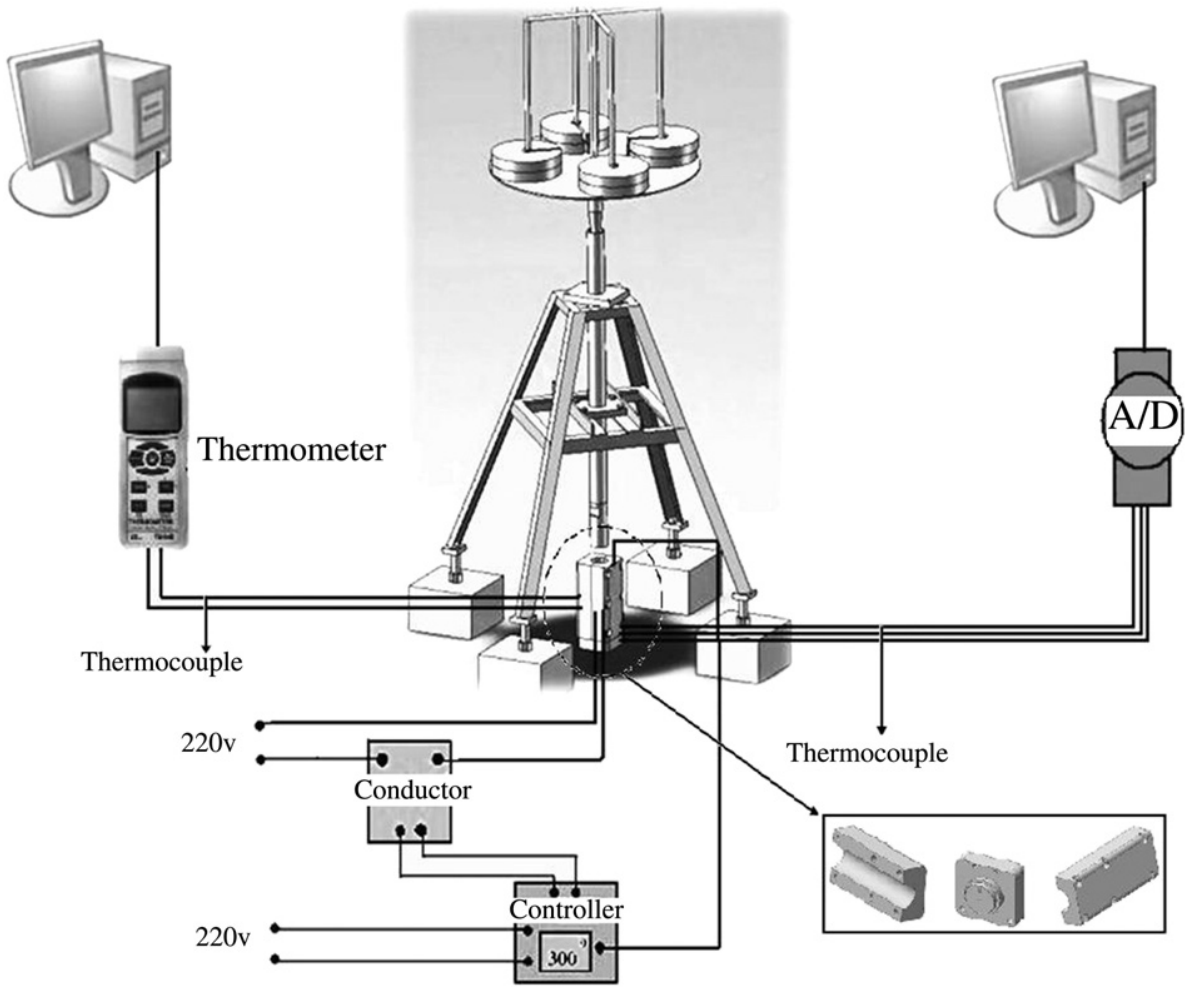

Fig. 4. Schematic representation of the experimental setup connected to the data acquisition and analysis system. 
The thermophysical properties of metal and mold for experimentation are summarized in Table 2. Temperature measurement was carried out using K-type thermocouples which are embedded both in mold and metal area. These thermocouples on the other side are connected to data acquisition system (DAQ) in personal computer by analog to digital (A/D) transformer. Mold dimension and five thermocouple layout (named A to E) are shown in Fig. 3. Experimental apparatus and also data gathering system are schematically shown in Fig. 4. Due to provide easier ejection of the casting from the mold after each test, the mold was built in three parts [17] as it illustrated in right-down corner of Fig. 4.

\section{Results and discussion}

In the case of casting made under atmospheric pressure the shrinkage defects were confined at the top of the casting (Fig. 5a), whereas for the castings made under pressure, these defects were trapped within the body of the castings (Fig. 5b and c). The forced thermal gradient which is made by ramrod creates a directionally solidifying media for the cast. As the external load increased the free surface (up surface) of the melt encounters the low temperature of ramrod. This makes the melt to solidify more and solidified layers move downward in to the middle of the melt.

Fig. 6 shows experimental temperature curves obtained through pouring aluminum into the mold without external load. The variation of $h$ with time it is mostly determined by the properties and geometry of the alloy that is cast along with the nature of the phase changes that take place in the casting during solidification. The thermocouples in this casting recorded oscillations in the first $5 \mathrm{~s}$ of the experiment which correspond to turbulent liquid flow in the bulk. The cooling curve data was read to the FDM program and the heat transfer coefficient for cylindrical surfaces was calculated as it illustrated in Fig. 7. As shown in Fig. 7 the empirical equations, relating interface heat transfer coefficients to the time, is: $h_{i}=4559 t^{-0.44}$
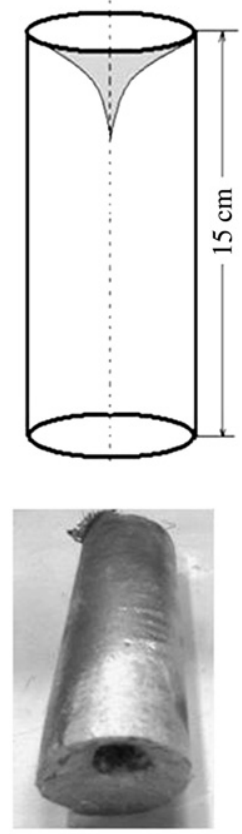

(a)
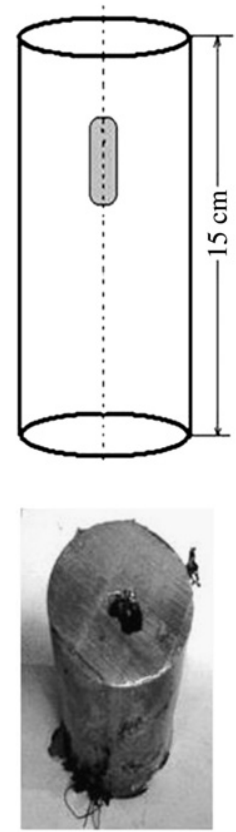

(b)
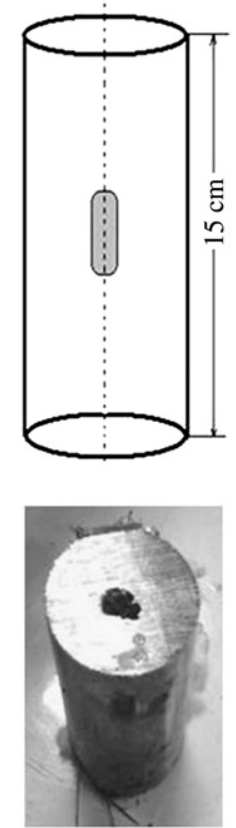

(c)

Fig. 5. Position of the shrinkages in the cast part. (a) At the top of the cast part (under atmospheric pressure). (b) Between the top and the middle of the cast part (1.14 MPa). (c) In the middle of the cast part (1.66 MPa).

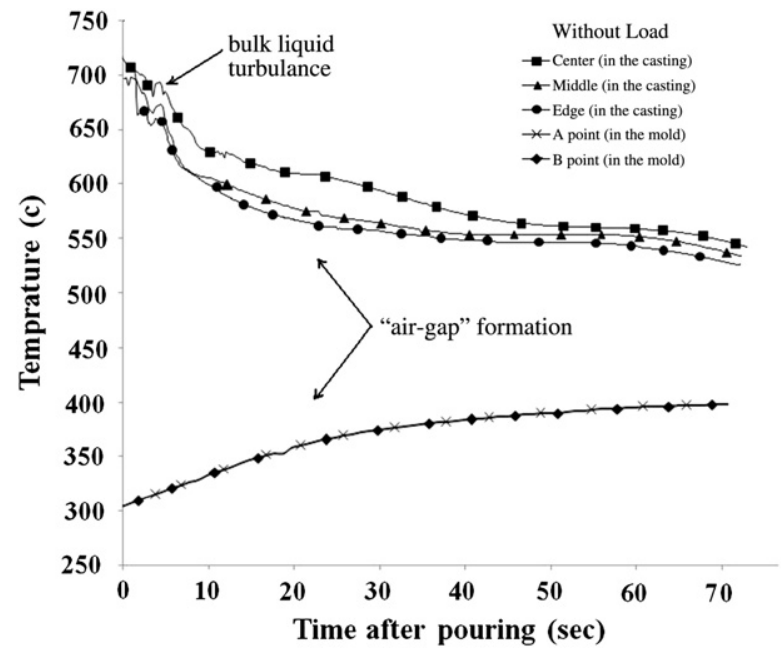

Fig. 6. Cooling curves of cast and mold body without any external pressure.

When the metal is completely liquid and has perfect contact with mold surface, the heat transfer coefficient reaches its maximum value of about $2885\left(w / m^{2} k\right)$ in no pressure application which shows good agreement with the last researches [18]. As the time passes a thin stable skin of solidified metal is formed on the outer layers of metal because the steel mold extracts heat from the molten metal. The interface is pressed against the mold by the hydrostatic pressure of the liquid metal, and results in decrease of IHTC. The IHTC reaches its minimum value after around $40 \mathrm{~s}$, which corresponds to solidification time ( $42 \mathrm{~s}$ estimated from cooling rate curves). This means that after about $40 \mathrm{~s}$ the contact between the casting and the die is transformed to solid-solid contact. The effect of hydrostatic pressure decreases with the increasing of the solid skin thickness. In this stage, some parameters, such as the wettability of the liquid on the mold surface, the amount of melt super heat, surface roughness, mold temperature, pouring momentum of melt, thermal conductivity of mold, hydrostatic pressure and turbulence of melt, affect the heat transfer coefficient. After formation of an adequate solid metal, the perfect contact between the mold and the solidified casting no longer exists because of contraction of the solidified casting. In addition, the thermal conductivity of the liquid is much higher than that of the solid. This makes decrease in amount of IHTC. Solidification orientation, thermal conductivity and surface roughness of the chill are the most

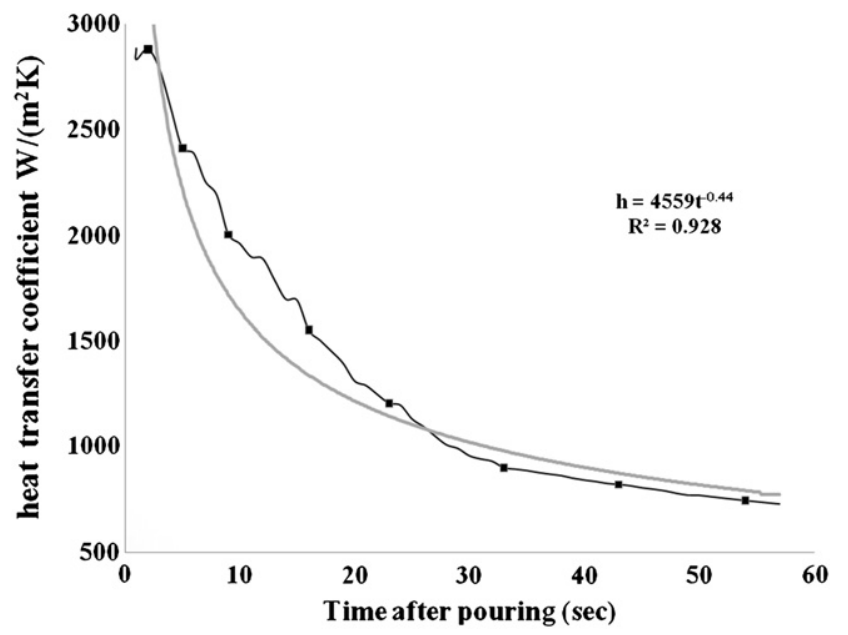

Fig. 7. The relationship between interfacial heat transfer coefficient and time (without load). 


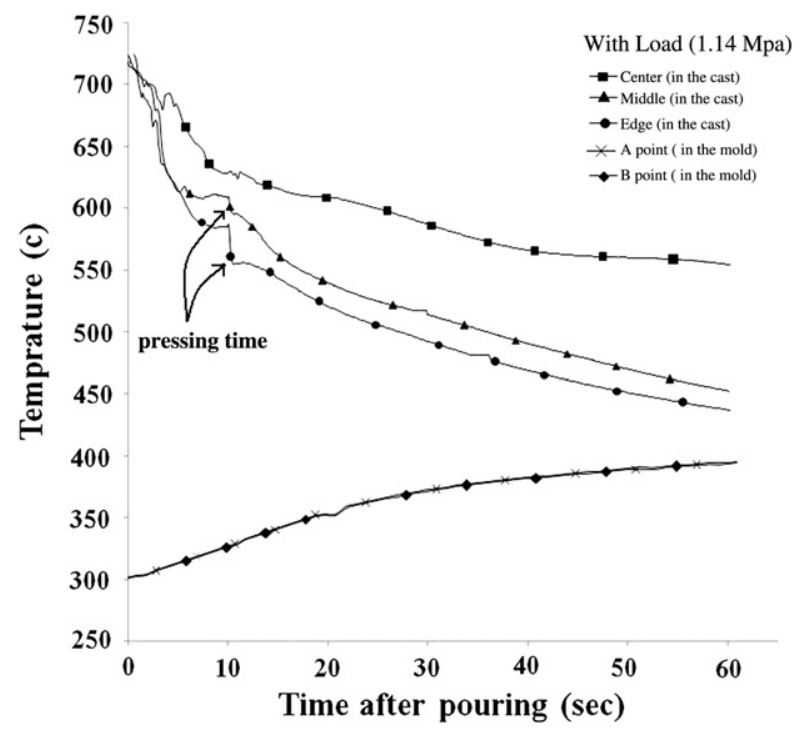

Fig. 8. Cooling curves of cast and mold body under 1.14 MPa pressure.

important parameters of the heat transfer coefficient in this stage of process.

Temperature curves obtained through applying a load of $1.14 \mathrm{MPa}$ after $10 \mathrm{~s}$ is shown in Fig. 8. The sharp drop down of the cooling curve in the edge point of molten metal is the clear effect of pressure usage. In the mentioned point, temperature decreases rapidly by the increase of heat loss, since the pressure accelerates the formation of the perfect contact. In other words, the quantity of heat which passes through the mold casting interface becomes greater in comparison with the no pressure usage. Another effect of external pressure is increase of cooling rate in the whole cast. Consequently the solidification time decreases. The other point is that the cooling curve in middle area of metal (marked with triangle) was also affected by presence of pressure, although it is around $10^{\circ} \mathrm{C}$. The IHTC for cylindrical surfaces in the presence of 1.14 MPa was determined and shown in Fig. 9. IHTC in the first $10 \mathrm{~s}$ with no pressure decreases as the time passes. After $10 \mathrm{~s}$ and application of pressure IHTC starts to increase. This agrees with the temperature drop down illustrated in Fig. 8. IHTC reaches it maximum value and then decreases as the fraction of solidified metal increased.

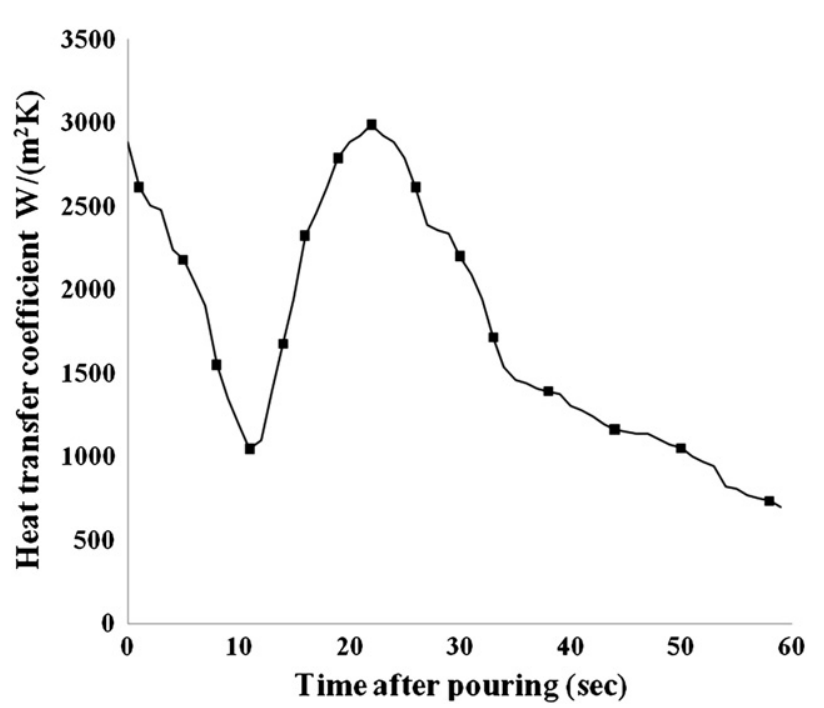

Fig. 9. Relationship between interfacial heat transfer coefficient and time in the presence of 1.14 MPa external pressure.

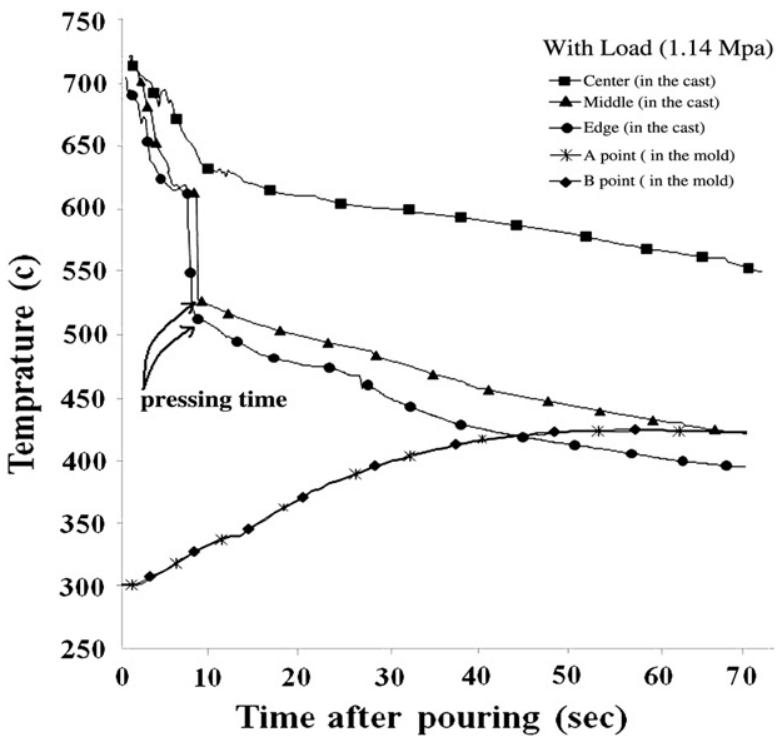

Fig. 10. Cooling curves of cast and mold body under 1.66 MPa pressure.

Application of more external pressure causes more increase of cooling rate for molten metal in the metal/mold interface and also whole cast. As it seen in Fig. 10 not only the cooling rates are increased, but also the heat content in the mold body is increased, since the heat pass from melt to mold is more. Calculated IHTC in the presence of $1.66 \mathrm{MPa}$ load is shown in Fig. 11. By the increase of pressure from 1.14 to $1.66 \mathrm{MPa}$ the maximum value of IHTC was increased from $2923\left(\frac{W}{m^{2} k}\right)$ to $3345\left(\frac{W}{m^{2} k}\right)$. To correlate the external pressure and IHTC, the maximum values of IHTC (around $22 \mathrm{~s}$ after pouring) were used to propose a new and simple formula. The empirical equation proposed to correlate between the IHTC and external pressure is written below:

$h=0.0011 P^{3}-0.112 P^{2}+6.605 P+2924.57$.

The data from literature was used to validate the proposed formula. Aweda and Adeyemi [19] evaluated the heat transfer coefficient during the squeeze casting of aluminum. Data values from the Aweda's work were obtained using point value measuring by GetData Graph

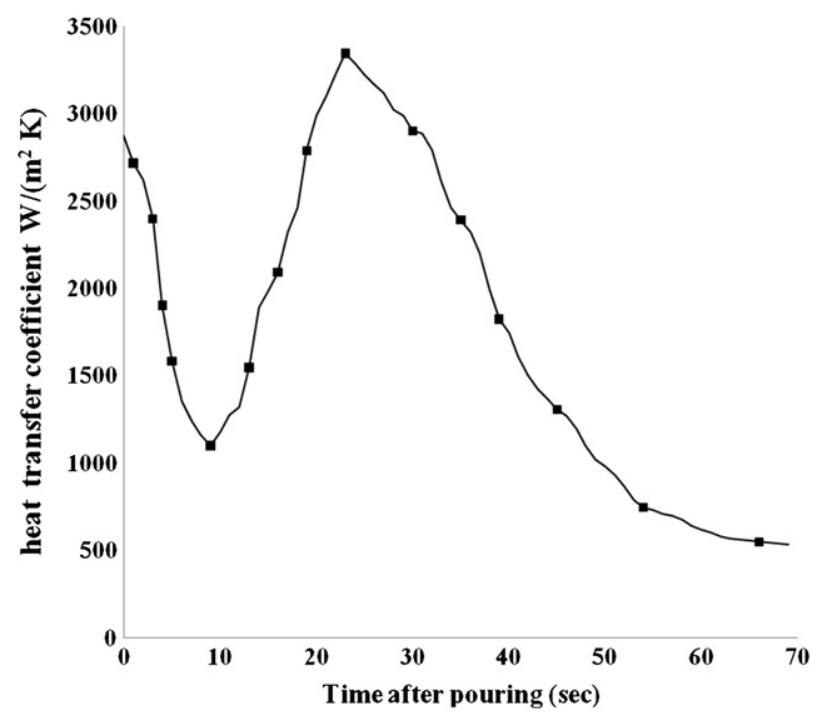

Fig. 11. Relationship between interfacial heat transfer coefficient and time in the presence of $1.66 \mathrm{MPa}$ external pressure. 


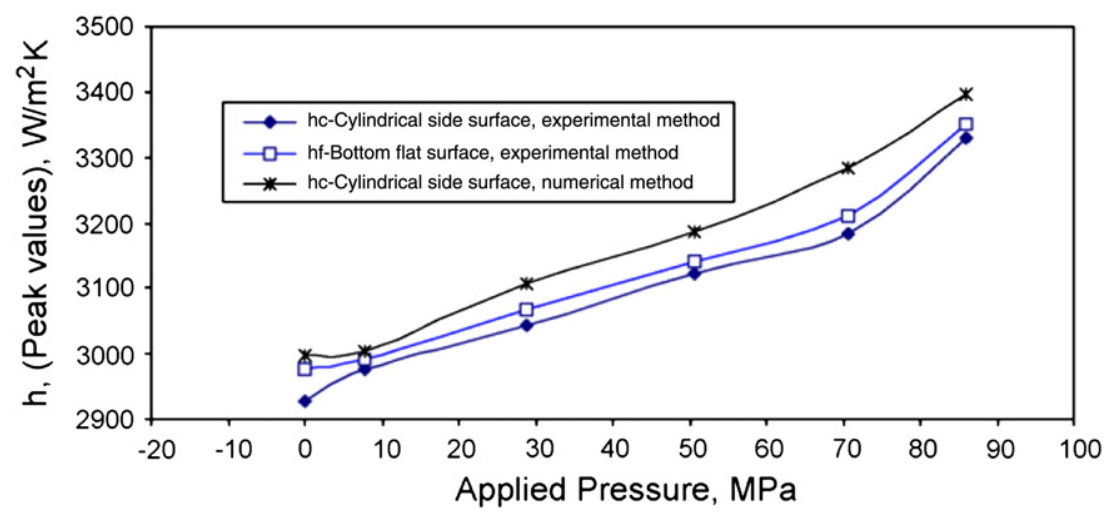

Fig. 12. Effect of pressure on the peak values of heat transfer coefficients of aluminum metal at liquidus stage [19].

Digitizer software. The proposed formula applied to their range of work and the results were compared with the experimental data which were carried out by them. Effect of pressure on the peak values of heat transfer coefficients of aluminum metal from Aweda's work was illustrated in Fig. 12. Fig. 13 shows the comparison between our proposed formula and data in literature [19].

\section{Conclusion}

Investigation on solidification of aluminum A356 alloy under different external loads shows that the pressure has remarkable effect on the heat transfer condition in the metal/mold interface. The main effect of the pressure relies in the variation of metal/mold contact, which varies from fully imperfect contact to perfect one. So as the pressure increases the probability of perfect contact increases and results in high cooling rates. These results were reported a lot in different academic papers, but the correlation between interfacial heat transfer coefficient (IHTC) and applied pressure was not formulated. A simple third order equation was proposed and compared with data in literature, which shows good agreement. Finally, from the present investigation the following conclusions can be made:

1) By increasing pressure, position of the shrinkages in the cast part changed, and shifts to down and trapped within the cast part.

2) Heat transfer from the casting to the mold was improved considerably by applying pressure load during solidification to make good contact between mold and casting.

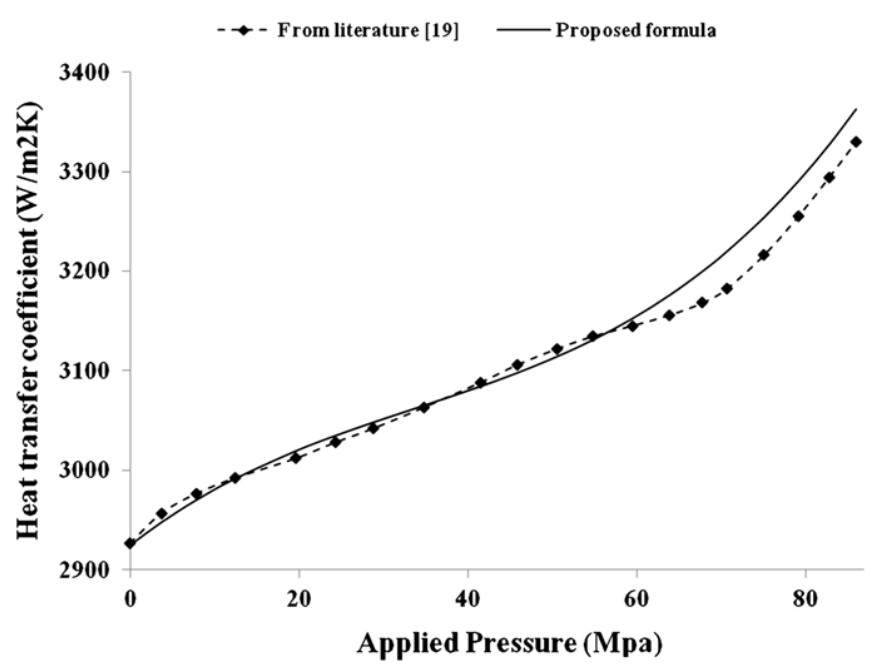

Fig. 13. Comparison of IHTC between proposed formula and literature.
3) In the case of no pressure existence, the heat transfer coefficient decreases as the time passes and their correlation is written below:

$h_{i}-4559 t^{-0.44}$.

4) As the external pressure increased the heat transfer coefficient increases. The empirical equations, relating interface heat transfer coefficients to the applied pressures are also derived:

$$
h=0.0011 P^{3}-0.112 P^{2}+6.605 P+2924.57 .
$$

\section{Acknowledgments}

Funding for this project was provided by the Razi Metallurgical Research Center. Its support is gratefully acknowledged. The authors are grateful for the research support of the Department of Materials Science and Engineering at Sharif University of Technology.

\section{References}

[1] J.H. Kuo, F.L. Hsu, Effects of mold coating and mold material on the heat transfer coefficient at the casting/mold interface for permanent mold casting of A356 aluminum alloy, AFS Transactions 01-061 (2001) 1-17.

[2] K. Ho, R.D. Pehlke, Metal-mold interfacial heat transfer, Metallurgical and Materials Transactions B 16 (1985) 585-594.

[3] M. Krishnan, D.G.R. Sharma, Determination of heat transfer coefficient between casting and chill in uni-directional heat flow, AFS Transactions 102 (1994) 769-778.

[4] C.A. Santos, Determination of transient interfacial heat transfer coefficients in chill mold castings, Journal of Alloys and Compounds 319 (2001) 174-186.

[5] M.A. Martorano, J.D.T. Capocchi, Heat transfer coefficient at the metal-mould interface in the unidirectional solidification of $\mathrm{Cu}-8 \% \mathrm{Sn}$ alloys, International Journal of Heat and Mass Transfer 43 (2000) 2541-2552.

[6] W.D. Griffiths, A model of the interfacial heat-transfer coefficient during unidirectional solidification of an aluminum alloy, Metallurgical and Materials Transactions B 31 (2000) 285-295.

[7] C.A. Santos, C.A. Siqueira, A. Garcia, J.M.V. Quaresma, Metal-mold heat transfer coefficients during horizontal and vertical unsteady-state solidification of $\mathrm{Al}-\mathrm{Cu}$ and Sn-Pb alloys, Inverse Problems and Engineering 12 (2004) 279-296.

[8] W.D. Griffiths, The heat transfer coefficient during the unidirectional solidification of an Al-Si alloy casting, Metallurgical and Materials Transactions B 30 (1999) 473-482.

[9] J.E. Spinelli, I.L. Ferreira, A. Garcia, Influence of melt convection on the columnar to equiaxed transition and microstructure of downward unsteady-state directionally solidified Sn-Pb alloys, Journal of Alloys and Compounds 384 (2004) 217-226.

[10] J.E. Spinelli, I.L. Ferreira, A. Garcia, Influence of melt convection on dendrite spacing of downward unsteady-state directionally solidified Al-Cu alloys, Materials Science and Engineering A 383 (2004) 271-282.

[11] Z.W. Chen, Skin solidification during high pressure die casting of Al-11Si-2Cu-1Fe alloy, Materials Science and Engineering A 348 (2003) 145-153.

[12] Hacı Mehmet Sahin, Kadir Kocatepe, Ramazan Kayıkcı, Neset Akar, Determination of unidirectional heat transfer coefficient during unsteady-state solidification at metal casting-chill interface, Energy Conversion and Management 47 (2006) 19-34.

[13] F.P. Incropera, D.P. Dewitt, Fundamentals of Heat and Mass Transfer, 3rd Ed., John Wiley \& Sons, Singapore, 1990, pp. 58-70.

[14] A. Hines, Determination of interfacial heat-transfer boundary conditions in an aluminum low-pressure permanent mold test casting, Metallurgical and Materials Transactions B 35 (2004) 299-310. 
[15] J.V. Beck, Nonlinear estimation applied to nonlinear inverse heat conduction problem, International Journal of Heat and Mass Transfer 13 (1970) 703-716.

[16] T. Loulou, E.A. Artyukhin, J.P. Bardon, Estimation of thermal contact resistance during the first stages of metal solidification process: I-experiment principle and modelisation, International Journal of Heat and Mass Transfer 42 (1999) 2119-2127.

[17] T.S. Piwonka, K.A. Woodbury, J.M. Wiest, Modeling casting dimensions: effect of wax rheology and interfacial heat transfer, Materials and Design 21 (2000) $365-372$.
[18] Y. Nishida, H. Matsubara, Effect of pressure on heat transfer at the metal moldcasting interface, Journal of British Foundaryman 69 (1976) 274-278.

[19] J.O. Aweda, M.B. Adeyemi, Experimental determination of heat transfer coefficients during squeeze casting of aluminum, Journal of Materials Processing Technology 209 (2009) 1477-1483. 